11.9-21.4 mcM). Treatment with valproic acid was not responsible for the low TC. TC was unrelated to a low blood glucose or time to achieve ketosis. A decrease in TC in the first months of diet treatment was followed by stabilization and a slight increase with long term treatment. None developed clinical signs of carnitine deficiency, and only $19 \%$ of patients received supplements of carnitine. An increased acyl/free carnitine ratio is dependent on the level of ketosis during $\mathrm{KD}$ treatment, and is not a useful measure for carnitine insufficiency. (Berry-Kravis E, Booth G, Sanchez AC, Woodbury-Kolb J. Carnitine levels and the ketogenic diet. Epilepsia Nov 2001;42:1445-1451). (Reprints: Dr E Berry-Kravis, Rush-Prebyterian-St Luke's Medical Center, 1725 West Harrison St, Suite 718, Chicago, IL 60612).

COMMENT. The majority of patients on the ketogenic diet do not develop low carnitine plasma levels, and those with low levels are asymptomatic. TC should be checked at 1 to 6 months of treatment, especially for patients with low-normal TC at $\mathrm{KD}$ initiation.

\title{
PAROXYSMAL TONIC UPGAZE: AGE OF ONSET AND PROGNOSIS
}

Six children who developed paroxysmal tonic upgaze (PTU) at 2.6 to 7.4 years of age were examined at least once per year for a 10 year period of followup at the Departments of Paediatrics and Ophthalmology, University of Chieti, Italy. Bouts of sudden sustained upward deviation of the eyes lasted for 10 to 20 seconds each, they appeared in small clusters, and were not associated with loss of consciousness. PTU was typically exacerbated by fatigue and relieved by sleep. Three patients were male and 3 female. Two had a febrile illness preceding the onset, 2 had a personal history of febrile seizures, $1 \mathrm{a}$ father with a history of febrile seizures, and $1 \mathrm{a}$ mother with migraine. One had an epileptiform interictal EEG, with temporo-occipital spikes, mainly in the left hemisphere. MRI, neurologic, and psychological examinations, including WISC-R or Stanford-Binet Intelligence Scales were normal. Episodes of PTU resolved spontaneously after 1 to 4 years, without treatment. (Verrotti A, Trotta D, Blasetti A et al. Paroxysmal tonic upgaze of childhood: effect of age-of-onset on prognosis. Acta Paediatr Nov 2001;90:1343-1355). (Respond: Dr Albert Verrotti, Department of Pediatrics-Policlinico Colle Dell'Ara, University G D'Annunzio, Via dei Vestini 5, IT-66013 Chieti, Italy).

COMMENT. The first description of the syndrome as "benign paroxysmal tonic upgaze of childhood" was reported in 4 patients by Ouvrier RA and Billson F (I Child Neurol 1988;3:177-180). Some subsequent reports have included associated neurologic abnormalities, including ataxia (Deonna $T$ et al. 1990), developmental delay, and abnormal brain MRI. Improvement following levodopa therapy in one child suggested a possible dystonia (see Progress in Pediatric Neurology II, PNB Publ, 1994;p146). Most patients have an early spontaneous resolution of the disorder. The authors suggest that the outcome may be age-dependent, their older patients having a more benign form of the syndrome than that described in younger infants. An immature cortico-mesencephalic control of vertical gaze is postulated as the pathophysiology.

\section{MOVEMENT DISORDERS}

\section{RIGHT FRONTAL WHITE MATTER AND TOURETTE SYNDROME}

An MRI volumetric analysis of frontal and nonfrontal gray and white matter was performed in 11 boys with Tourette syndrome (TS) only, 14 with TS + ADHD, 12 with ADHD only, and 26 healthy boys, at the Kennedy Krieger Institute, 
Baltimore, MD. Ages ranged from 7.0 to 15.5 years. Using $2 \times 2$ multivariate factorial analysis of variance (MANOVA), which characterized subjects for presence or absence of TS and ADHD, and various combinations, the effects of TS status, ADHD status, and the interaction of these two factors on frontal lobe white and gray matter volumes were determined. In subjects with TS, the right frontal lobe had a larger proportion of white matter, and the right frontal white matter volume was increased. ADHD was associated with a reduction in frontal lobe volumes that was attributable to decreased gray matter, especially in the left frontal lobe. The findings support a frontostriatal pathophysiology of Tourette syndrome. (Fredericksen KA, Cutting LE, Kates WR et al. Disproportionate increases of white matter in right frontal lobe in Tourette syndrome. Neurology January (1 of 2) 2002;58:85-89). (Reprints: Dr Walter E Kaufmann, Department of Developmental Cognitive Neurology, The Kennedy Krieger Institute, $707 \mathrm{~N}$ Broadway, Room 522, Baltimore, MD 21205).

COMMENT. An increase in white matter in the right frontal lobe of patients with Tourette syndrome is in keeping with previous reports by the same authors of an enlarged rostrum of the corpus callosum associated with TS (Baumgardner TL et al. 1996; see Progress in Pediatric Neurology III, PNB Publ, 1997;pp322-323). In contrast, boys with $\mathrm{ADHD}$ were found to have a significant decrease in size of the corpus callosum rostral body. The effects of ADHD and TS on corpus callosum size were statistically independent.

\section{ATTENTION DEFICIT DISORDER}

\section{DOPAMINE RECEPTOR AVAILABILITY IN ADHD}

Striatal dopamine (D2) receptor availability was determined by iodobenzamide brain SPECT, before and 3 months after methylphenidate (MPH) therapy, in 9 children (mean age, 9.8 years) with attention deficit hyperactivity disorder (ADHD) examined at Gazi University, Ankara, Turkey. Specific D2 receptor binding ratios in $\mathrm{ADHD}$ subjects at baseline were higher than those reported in healthy young adults. Severity of ADHD behavioral symptoms was correlated with D2 receptor levels; the higher the Conners Teacher Rating Scale scores, the higher the baseline D2 availability in the putamen and caudate. D2 receptor availability was significantly reduced in all four regions of the striatum following MPH therapy. The higher the baseline D2 levels, the greater the behavioral response to MPH (as determined by improved hyperactivity and Conners Teacher Rating scores), whereas the response in attention deficit scores was not related to baseline D2 levels. D2 receptor levels in patients with ADHD may predict the behavioral response to MPH. (Ilgin N, Senol S, Gucuyener K et al. Is increased D2 receptor availability associated with response to stimulant medication in ADHD? Dev Med Child Neurol Nov 2001;43:755-760). (Respond: Dr N Ilgin, PK 61 Bahcelievler, 06500 Ankara, Turkey).

COMMENT. D2 receptor levels are higher than normal in untreated children with $\mathrm{ADHD}$, and are reduced to near-normal values following treatment with methylphenidate. The higher the pre-treatment D2 receptor availability, the greater the severity and number of ADHD behavioral symptoms and the better the behavioral response to therapy. These findings are in accord with previous reports of clinical predictors of response to MPH therapy in ADHD (Millichap JG, Ann NY Acad Sci 1973; in Attention Deficit Hyperactivity and Learning Disorders, PNB Publ, 2001). Children who are most active are most likely to respond to MPH. 